\title{
Acreditação no âmbito da assistência farmacêutica hospitalar: uma abordagem qualitativa de seus impactos
}

\author{
I ${ }^{1}$ Esterlita Bouças, ${ }^{2}$ Thaiane Reis Martins, ${ }^{3}$ Debora Omena Futuro, \\ ${ }^{4}$ Selma Rodrigues de Castilho I
}

Resumo: Este estudo analisa o impacto do processo de acreditação na assistência farmacêutica hospitalar, visando identificar evidências de mudanças e melhorias do serviço prestado pela farmácia hospitalar. Grupos focais foram conduzidos com farmacêuticos e clientes internos do serviço de farmácia de cinco hospitais privados do Estado do Rio de Janeiro intencionalmente selecionados. Foram realizadas gravaçóes, posteriormente transcritas, para análise do conteúdo dos diálogos e categorização temática. Segundo as narrativas revelaram, a acreditação resultou em investimentos de infraestrutura e recursos humanos, implantação de novos processos e discreta mudança de atuação do farmacêutico, alavancada pela farmácia clínica. Observou-se que tais modificaçôes contribuíram para uma transformação contínua da assistência farmacêutica hospitalar, com modesta melhora da eficiência, qualidade e segurança do serviço prestado. Quando considerados os resultados finalísticos, a satisfação foi parcial, já que o ciclo da assistência farmacêutica ainda não se completa, fragilizando os processos recém-implantados em prol da qualidade do atendimento oferecido ao paciente. Apesar disso, o impacto no desempenho global da farmácia hospitalar foi considerado positivo, permitindo concluir que as diretrizes da acreditação apontaram o caminho para o desenvolvimento dos serviços avaliados, na medida em que exigiram o cumprimento de padróes necessários a uma assistência farmacêutica de qualidade.

> Palavras-chave: Avaliação em saúde; acreditação; assistência

\author{
' Fundação Dom André \\ Arcoverde, Centro de Estudo e \\ Pesquisa em Atenção Básica à \\ Saúde. Valença-RJ, Brasil (carol_ \\ reigada@yahoo.com.br). \\ ORCID: 0000-0001-9621-4908. \\ ${ }^{2}$ Universidade Federal do Rio de \\ Janeiro. Rio de Janeiro-RJ, Brasil \\ (valeriaromano34@gmail.com). \\ ORCID: 000-0002-6646-2879
}




\section{Introdução}

Os hospitais brasileiros passaram por diversas mudanças ao longo dos últimos anos que resultaram em novas formas de gestão e reestruturação dos serviços, com foco na avaliaçáo da qualidade da assistência prestada, com o objetivo de melhorar a produtividade ea segurança dos pacientes. A qualidade, antes considerada desejável, passa a ser um atributo imprescindível para obtenção de bons resultados em termos de qualidade dos serviços de saúde prestados, de modo a atender, principalmente, às expectativas dos clientes, por se tratar de um elemento diferenciador (MANZO, 2012; RODRIGUES, 2004).

Nessa perspectiva, surge a acreditação hospitalar, uma metodologia de avaliaçãodesenvolvida para garantir a qualidade da assistência oferecida em todos os serviços de um hospital, tendo em vistaa melhoria da utilização dos recursos e prestação de serviços de saúde, à medida que defende e promove mudanças comportamentais, mobilização gerencial, inovaçôes estruturais e tecnológicas dos hospitais (RODRIGUES, 2004).

A acreditação exerce papel importante no cenário brasileiro caracterizado como uma forma de representar a melhoria da qualidade e segurança da prestação de serviços (BRITO et al.,2017). O surgimento da acreditação tem mostrado, nas últimas décadas, a importância da participação de instituições de saúde, a exemplo dos hospitais, como forma de um processo estratégico dessas empresas, para ganhar notoriedade no mercado brasileiro.

No Brasil, o processo de acreditação é um processo voluntário. Segundo dados do estudo de Brito e colaboradores (2017), o número de hospitais brasileiros acreditados não chega a 5\%, e apesar de significativo para o mercado de saúde, geralmente ainda é restrito a hospitais do setor privado. O Programa Brasileiro de Acreditação é conduzido pela Organização Nacional de Acreditação (ONA), que estabelece padróes de referênciapara os serviços de saúde, além de monitorar o processo de certificação, realizado por instituições acreditadoras credenciadas (SCHIESARI, 1999). O programa visa o amplo conhecimento a respeito do processo permanente de melhoria da qualidade assistencial, mediante avaliação periódica do serviço de saúde, com base no Manual Brasileiro de Acreditação Hospitalar (FELDMAN et al., 2005).

A farmácia hospitalar, como parte integrante dos serviços de saúde, tem sua estrutura e atividades desenvolvidas, baseadas nas características e complexidade das 
organizaçôes hospitalares. Sua sistematização está diretamente relacionada com o tipo de assistência prestada pelo hospital (MESSEDERet al., 2007). Historicamente, os procedimentos de aquisição e distribuição de medicamentos consolidaram-se como foco das atividades da farmácia hospitalar brasileira (BRASIL, 2009). Mais recentemente, a assistência farmacêutica hospitalar ganhou destaque nas discussóes institucionais e acadêmicas, sendo inserida no conjunto das açôes de saúde, por centralizar sua atenção no paciente e suas necessidades, mantendo não só o medicamento como foco de trabalho, mas também o paciente como um todo (SANTANA, 2013).

No entanto, apesar da expansão do processo de acreditação, grande parte das farmácias hospitalares brasileiras apresentaainda baixo desempenho, e seu desenvolvimento ao longo dosanosocorreu de forma pontual e não planejada, permitindo a coexistência de realidades muito distintas em relação à prestação de serviços farmacêuticos desejáveis (OSÓRIO-DE-CASTRO; CASTILHO, 2004; MESSEDER et al., 2007; SANTANA, 2013). Esforços do Ministério da Saúde e de sociedades competentes no assuntobuscam assegurar a implantação e o monitoramento de leis, políticas e recomendaçôes que assegurem o uso seguro e racional de todas as tecnologias utilizadas na prestação da assistência ao paciente, assim como o pleno desenvolvimento da farmácia hospitalar.

Nesse contexto, parece haver consenso de que a acreditação atua como promotora de mudanças organizacionais, dessa forma, as diretrizes da acreditação para os serviços de saúde podem apontar o caminho para o aprimoramento das farmácias hospitalares brasileiras, na medida em que exigem o cumprimento da legislação e de padrôes necessários à efetiva promoção de resultados clínicos, econômicos e sociais, transformando-se, assim, em um instrumento facilitador para a conquista de uma assistência farmacêutica pautada na qualidade e segurança de seus usuários (SILVA, 2003; GONSALVES, 2012; MENDES; MIRANDOLA, 2015).

Dessa maneira, o objetivo do presente estudo consiste em identificar e descrever o efeito do processo de acreditação na assistência farmacêutica em serviços de farmácia de hospitais privados, sob a perspectiva de profissionais de saúde.

\section{Materiais e métodos}

Trata-se de um estudo de casos múltiplos, no qual foram selecionados hospitais privados, ligados a uma mesma operadora de saúde, localizados no Estado do Rio 
de Janeiro, com certificados de acreditação validados e homologados pela ONA até abril de 2012. Com base neste critério, seis unidades estavam aptas a compor os casos da pesquisa. Entretanto, uma delas recusou-se a participar, reduzindo o universo para um total de cinco hospitais.

A técnica do grupo focal foi aplicada a dois grupos, em momentos distintos: um de farmacêuticos e outro dos clientes internos do serviço de farmácia, aqui representados por gerentes de enfermagem e gestores da qualidade. A composição de cada grupo baseou-se na existência de, ao menos, um ponto de semelhança entre os participantes, representado, nesse caso, pelas atividades desenvolvidas no hospital. O critério de inclusão dos entrevistados foi ter participado do processo de acreditação na unidade hospitalar com que possuía vínculo. Como critério de exclusão, foi considerado apenas o fato de o profissional ter sido transferido ou desligado da instituição durante o processo de acreditação, não tendo, portanto, vivenciado sua conclusão. Cada participante foi identificado através de código alfanumérico, correspondente ao seu cargo e hospital de origem, garantindo o sigilo e a preservação do anonimato. Sendo assim, os gestores farmacêuticos foram denominados como GF, gestores de enfermagem como GE e gestores da qualidade como GQ.

O ambiente dos dois encontros, um com cada grupo, respeitou a privacidade e o acolhimento necessários para a liberdade da expressão, bem como o conforto e relaxamento para a dinâmica do grupo. Para tanto, aconteceufora do local de trabalho dos participantes, em dias e horários apropriados, conforme a disponibilidade geral, de forma a garantir uma maior participação dos sujeitos e assim obter maior riqueza de dados.

O grupo focal foi conduzido por um moderador, que discutiu os aspectos éticos vinculados ao estudo e obteve assinatura do termo de consentimento livre esclarecido de cada um dos participantes presentes. Além disso, esclareceu a dinâmica das discussóes, estimulando o debate para garantir a efetiva interação entre todos os convidados. Para isso, foram empregados roteiros estruturados, norteadores do encontro, contendo as questóes a serem tratadas (tabela 1). 
Tabela 1. Perguntas norteadoras dos grupos focais.

\begin{tabular}{|c|c|}
\hline Grupo envolvido & Perguntas norteadoras \\
\hline Farmacêuticos & $\begin{array}{l}\text { Quais mudanças você percebeu nas atividades do serviço de farmácia, } \\
\text { como fruto da acreditaçáo, e como elas afetaram seu serviço? } \\
\text { Que elementos facilitaram a adequaçáo do seu serviço no processo } \\
\text { de acreditação e quais obstáculos você encontrou para conduzir a } \\
\text { acreditação na FH? } \\
\text { Hoje, como você avalia o desempenho da farmácia em relaçáo à eficiência, } \\
\text { confiabilidade, acessibilidade e segurança da assistência prestada? } \\
\text { Como você avalia a contribuiçâao da farmácia na qualidade do } \\
\text { atendimento global oferecido ao paciente? } \\
\text { Que impactos a acreditação trouxe para a assistência farmacêutica em } \\
\text { seu hospital? } \\
\text { De que forma a acreditaçáo contribuiu para o seu aprimoramento } \\
\text { profissional? } \\
\text { Como você se considera atualmente, frente aos serviços da FH, após o } \\
\text { processo de acreditaçáo? }\end{array}$ \\
\hline $\begin{array}{l}\text { Partes } \\
\text { Interessadas } \\
\text { (stakebolders) }\end{array}$ & $\begin{array}{l}\text { De um modo geral, como você se considerava, frente ao serviço da } \\
\text { FH, antes do processo de acreditaçáo? } \\
\text { Quais mudanças você percebeu nas atividades do serviço de farmácia, } \\
\text { como fruto da acreditaçáo? } \\
\text { De que modo estas mudanças, impostas pela acreditação na farmácia, } \\
\text { afetaram o seu próprio trabalho? } \\
\text { Hoje, como você avalia o desempenho da farmácia em relação à eficiência, } \\
\text { confiabilidade, acessibilidade e segurança da assistência prestada? } \\
\text { Como você avalia a contribuiçâo da farmácia na qualidade do } \\
\text { atendimento global oferecido ao paciente e clientes internos? } \\
\text { Como você se considera atualmente, frente aos serviços da FH, após o } \\
\text { processo de acreditação? }\end{array}$ \\
\hline
\end{tabular}

O grupo focal também contou com a participação de dois observadores, que registraram a dinâmica grupal e atuaram no controle do tempo e monitoramento dos equipamentos de gravação. Todas as seçôes tiveram áudio e vídeo gravados, visando assegurar maior fidedignidade na reprodução do discurso dos participantes. Posteriormente, as gravaçóes foram transcritas, por profissional especializado e 
contratado exclusivamente para esta finalidade, a fim de garantir o registro literal de todas as falas, para análise e elaboração do relatório final de pesquisa, respeitando os aspectos éticos. Sendo assim, cada depoimento foi examinado a partir de diferentes perspectivas, a fim de captar, compreender e analisar os conhecimentos gerados pelo grupo focal.

Foram realizados dois encontros, um com cada grupo, com duração aproximada de duas horas e trinta minutos, que contaram com uma participação homogênea dos convidados, não sendo necessário o estímulo à fala pela moderadora, garantindo o respeito mútuo e a interatividade dos participantes. Através da análise dos discursos obtidos após a etapa de transcrição, foram extraídos os temas centrais discutidos pelos participantes, empregando-se a compilação por semelhança e o agrupamento por dimensóes (CAMPOS, 2004). Dessa forma, emergiram três dimensōes, divididas da seguinte maneira: Efeito da acreditação na farmácia hospitalar; Contribuições da acreditação e Obstáculos para o desenvolvimento da assistência farmacêutica.

O presente trabalho foi submetido e aprovado pelo Comitê de Ética em Pesquisa do Hospital Universitário Antônio Pedro, sob o parecer no 167.129.

\section{Resultados}

Vinte profissionais de saúde, de diferentes categorias, foram convidados a participar da pesquisa. Embora, inicialmente, todos tenham aceitado colaborar com o estudo, apenas doze efetivamente compareceram aos encontros para realizaçáo do grupo focal. As faltas ocorreram em razão de imprevistos na agenda dos convidados $(n=4)$, férias $(n=2)$ e desistência em participar da pesquisa $(n=2)$. Houve mais de uma tentativa de reagendamento das atividades, o que não alterou o cenário de faltas, levando à realização dos encontrosem datas convenientes à maioria dos participantes. As características dos participantes que tomaram parte do grupo focal estão detalhadas na tabela 2 . Os sujeitos são, em sua maior parte, do sexo feminino ( $\mathrm{n}=7)$, com idade média de 41 anos $(\mathrm{DP}=9,22)$ e atuaçáo institucional média de 7,8 anos $(\mathrm{DP}=8,51)$. 
Tabela 2. Caracterização dos participantes, N=12. Rio de Janeiro (RJ), Brasil, 2013.

\begin{tabular}{l|l|l}
\hline \multicolumn{2}{l|}{ Dados dos participantes } & N \\
\hline \multirow{4}{*}{ Formação Profissional } & Farmacêutico & 06 \\
\cline { 2 - 3 } & Enfermeiro & 04 \\
\cline { 2 - 3 } & Fisioterapeuta & 01 \\
\cline { 2 - 3 } & Médico & 01 \\
\hline \multirow{4}{*}{$\begin{array}{l}\text { Cargo exercido na unidade de } \\
\text { origem }\end{array}$} & Gestor Farmacêutico (GF) & 05 \\
\cline { 2 - 3 } & Farmacêutico Assistente (FA) & 01 \\
\cline { 2 - 3 } & Gestor da Qualidade (GQ) & 03 \\
\cline { 2 - 3 } & Gerente de Enfermagem (GE) & 03 \\
\hline \multirow{4}{*}{ Idade } & $20-30$ anos & 01 \\
\cline { 2 - 3 } & $30-40$ anos & 04 \\
\cline { 2 - 3 } & $40-50$ anos & 05 \\
\cline { 2 - 3 } & $>50$ anos & 02 \\
\hline
\end{tabular}

Quanto aos hospitais, todos estão localizados no Estado do Rio de Janeiro, e a maioria é de grande porte $(n=3)$. A acreditaçáo ocorreu em períodos variados da história de cada unidade, como reflexo da busca pela humanização e excelência em seus serviços, aliada à competitividade e reconhecimento de mercado. Ressalta-se o fato de que, em dois desses hospitais, também foram obtidos os selos de acreditação internacional, emitidos pelo Canadian Concil of Acreditation, no ano de 2012, fato que reflete e reforça a busca pela qualificação e segurança do serviço prestado.

Os resultados, detalhados a seguir, foram ordenados por categorias temáticas, ilustradas com pequenos extratos dos depoimentos colhidos nas gravaçôes.

\section{Efeito da acreditação na farmácia hospitalar}

Na visão dos farmacêuticos, a acreditaçáo afetou positivamente no desempenho da farmácia hospitalar, especialmente quando comparado com o momento anterior à certificação, embora reconheçam, em partes, que ainda há um longo caminho a percorrer. 
Estamos no ideal? Náo. Mas, comparativamente a antes da acreditaçâo, melhorou sem dúvida. Porque não tinha nem farmacêutico! Passei a ter farmacêutico, a fazer uma série de atividades que podem parecer básicas, mas que eu não fazia (GF02).

A gente ainda não conseguiu chegar ao fim, não conseguiu estar em todas as etapas do monitoramento (GF01).

A percepção geral dos clientes internos é de que a farmácia hospitalar se esforça em construir uma nova forma de trabalhar em prol da segurança dos pacientes, adaptando-se às práticas, preconizadas pela acreditação, para uma assistência farmacêutica de qualidade.

Quando você começa a notificar e ver as tratativas dessas notificaçóes, você vê que teve melhorias. Quando o grupo é participativo e está imbuído dessa eficácia, você vê que as notificaçóes começam a diminuir e não é por falta de estímulo de notificar ou por uma parte punitiva. É porque os processos estáo se organizando [...](GQ05).

Outra vertente sinalizada pelos atores foi que houve importantes adequaçóes relacionadas à estrutura física, ao quadro de farmacêuticos e aparatos tecnológicos na farmácia hospitalar, embora não tenham acontecido de forma igualitária em todas as unidades.

Prescrição eletrônica, código de barras, rastreabilidade. Não tem conversa; hoje sem o sistema eletrônico, não vai [...]. Agora, em estrutura física, ainda não mudei nada e é apontada toda vez como uma não conformidade, mas em serviço foi abissal, assim, tomou outra dimensão. Eu ganhei muito mais em processo (GF01).

O que eu sinto de imediato foi além, desde a mudança de efetivo de farmacêuticos, porque com a demanda das atividades multidisciplinares da acreditação, a gente acaba tendo que ter um aumento do quadro de farmacêuticos e isso eu acho bem positivo. Tem essa parte de infraestrutura também, porque a farmácia, muita das vezes, fica negligenciada em termos de investimento e com o processo de acreditaçáo, a gente consegue realmente defender a necessidade de ter os mobiliários, os espaços adequados [...] gente consegue ter uma farmácia realmente com cara de farmácia hospitalar e não somente como um estoque que está ali escondidinho (GF03).

\section{Contribuiçôes da acreditação}

De acordo com o relato dos participantes, a acreditação favoreceu a reintrodução do farmacêutico no cenário assistencial, deixando lentamente de ser um mero fornecedor de medicamentos e insumos e passando a atuar como membro integrador da equipe multiprofissional. Os relatos deixam claro que o foco do trabalho do farmacêutico tem mudado da visão elementar de dispensar medicamentos para o monitoramento do cuidado do paciente. 
Acho que esse modelo da acreditação veio trazer o foco assistencial, colocar a assistência farmacêutica mais em evidência. E acho que aí há a grande mudança de paradigma da farmácia da época, no meu entendimento, para o modelo atual, alavancado pela acreditação, que é o de trazer o modelo farmacêutico mais com foco na assistência (GE05).

Todo o meu setor com a acreditaçáo foi muito mais longe. Não existia essa cultura. Eu era um simples almoxarifado e passei a ser um serviço de farmácia hospitalar, inserido na assistência. A gente queria muito ser visto como profissional de saúde, não almoxarife, e de quebra a acreditação traz isso. [...] Todo mundo entendeu que se a farmácia não for acreditada, o hospital também não vai (GF02).

A crescente inserção do farmacêutico na equipe multiprofissional promoveu maior visibilidade de seu trabalho, de forma a despertar uma perspectiva profissional e, consequentemente, a cobrança por parte da qualidade do serviço.

Isso é o lado positivo que a acreditação trouxe para a qualidade, só que o lado oposto tem essa questão da expectativa. Agora a gente quer mais, isso que você já está fazendo é muito pouco, a gente espera mais de vocês e aí essa diferença do que eu quero e o que você pode me dar é a grande confusão (GE05).

Para os farmacêuticos, o maior ganho está na mobilização institucional provocada pela acreditação, que, apesar do apelo mercadológico e pela sustentabilidade empresarial, permitiu o reconhecimento da importância da farmácia hospitalar e alavancou algumas mudanças na estrutura, no organograma e nos processos, afetando direta e positivamente o trabalho dos farmacêuticos.

A gente faz todos os protocolos, a gente faz retirada de acesso precoce, o antibiótico está como injetável, a gente coloca por oral. Então, impactou sim no cuidado (GF01).

A legislação hospitalar brasileira não conseguiu um efeito tão forte quanto à acreditação. Isso eu não tenho dúvida! É mercado, é marketing! (GF02).

Os farmacêuticos ressaltaram como contribuição relevante desse processo o grande crescimento e o amadurecimento profissional, relatados, a princípio, com grande entusiasmo.

Mudou a minha vida. Sou outra pessoa, seis anos parece que eu passei vinte. Mudou tudo, crescimento, amadurecimento, botar a cara para bater, estar de frente com a família, ir para outra acreditação, brigar pelo que você quer, você acreditar, discordar da acreditação, falar que não é assim... (GF01).

Sem dúvida. Acho que mudou bastante. O meu crescimento profissional acho que foi grande (GF03).

De forma generalizada, as mudanças mais evidentes, para farmacêuticos e seus clientes, estão relacionadas ao aprimoramento contínuo dos processos, resultando 
no incremento da execução de atividades importantes para um serviço de farmácia hospitalar, em especial, a farmácia clínica.

A gente vê muito bem, os setores que tiveram piloto de farmácia clínica, eles alavancaram e isso trouxe uma lição da porta pra dentro para eles começarem a redesenhar alguns processos (GQ01).

Muitas vezes não se ouvia falar do farmacêutico, não se conhecia o farmacêutico, não tinha a cultura de o farmacêutico rodar pelo hospital, conversar com os médicos, fazer a intervenção, ter a intervenção aceita, de notificar em prontuário, como que ele pode melhorar a assistência daquele paciente com o conhecimento dele [...] a acreditaçáo possibilitou isso tudo (GF03).

\section{Obstáculos para o desenvolvimento da assistência farmacêutica}

Apesar das mudançassignificativas em decorrência do processo de acreditação, houve unanimidade na percepção dos atores de que a assistência farmacêutica ainda está muito centrada na questão logística e no gerenciamento de custos, apontado como reflexo de anos de estagnação profissional e da falta de apoio dos próprios gestores da administração.

Se a alta administração não anda em conformidade com o que está sendo exigido de uma acreditação, como a gente faz? (GF01).

[...] Nós ainda temos aquela coisa do dinheiro ali com a gente. Como temos $60 \%$ do dinheiro ali com a gente, é muito mais fácil deles entenderem que a gente é setor de controle de custo do que um setor de prestação de serviços farmacêuticos e de assistência. $[\ldots](\mathrm{GF} 02)$.

A farmácia começa a entender que o papel dela é importante também da porta pra fora, mas não consegue avançar para o modelo, ainda por um entendimento da administração engessado. A assistência fala, os gestores médicos falam da necessidade, mas eles não conseguem se unir pra lutar por aquilo de uma forma uníssona, entendeu, acho que a gente tá vivendo particularmente uma situação de caos controlado (GQ01).

Um dos entrevistados ressaltou ainda um impasse, no processo de acreditaçáo, em que, mesmo sendo apontadas não conformidades, o selo é concedido. Essa ação provoca descontentamento por parte dos farmacêuticos, levando ao desgaste profissional, e gera dúvidas a respeito do processo.

Apesar de ser uma não conformidade apontada em toda visita, ela nunca me impediu de ser acreditada[...]. E quando você vê que a acreditaçáo não traz uma mudança efetiva numa cultura administrativa, aí você começa até a duvidar daquilo. Será que isso é puramente mercadológico? Juro. Eu tenho várias críticas (GF01). 
$\mathrm{Na}$ visão das partes interessadas, as mudanças ocasionadas pela acreditação ainda não ficaram claras, não sendo evidentes os benefícios reais para o atendimento prestado ao paciente por parte da farmácia.

Eu ainda não consigo ver toda essa contribuição da farmácia em relação à qualidade
de atendimento. Eu consigo ver a do médico, eu consigo ver a da enfermagem, a do
fisioterapeuta, mas da farmácia, para o paciente, não, não consigo (GQ04).
É preocupante a gente não conseguir tangibilizar a importância ou o valor da
contribuiçáo da farmácia dentro da qualidade. Talvez a acreditação passe e você não
perceba a mudança (GE05).

Para os clientes internos, a qualidade do serviço farmacêutico ainda está muito voltada para a dispensação. O fato de ter o medicamento disponível, e no horário correto, ainda é o conceito formado do trabalho da farmácia hospitalar.

O foco é muito mais a dispensação do que a assistência, óbvio. Essa é uma grande discussão nossa aqui, já que almejamos uma participação maior e mais efetiva na área assistencial. A equipe de enfermagem, em uma análise geral, ela está muito mais interessada em ter uma dispensação coerente, do que ter uma assistência farmacêutica. Já que é ela que administra, é ela que monitora os efeitos indesejados, as reaçôes adversas, ela que notifica. Então, ela prefere ter o produto na máo, para poder fazer na hora certa, da maneira certa e não atrasar o trabalho dela. Se o farmacêutico vai interagir, isso não é percebido ainda na realidade (GE05).

Outro ponto abordado, e reforçado pela acreditação, é a interação do farmacêutico na assistência à saúde do paciente. No entanto, a falta de treinamento adequado do farmacêutico nessa áreae a carência na formação acadêmica, sobretudo em relação aos aspectos clínicos, contribuem para a dificuldade de interação com a equipe de saúde.

A acreditação também ajudou bastante para isso [interação com a equipe] e sem dúvida o trabalho do farmacêutico deixa de ser aquela pessoa, aquele trabalho burocrático para ser inserido de fato na clínica, e aí acho que a dificuldade da gente, que a gente começa a ver as defasagens realmente na nossa formação, que a gente não tem uma formação voltada pra assistência ao paciente, clínica, conhecimento de material, utilização de materiais e aí que se faz importante salientar as atividades multidisciplinares até para gente agregar conhecimento e a gente poder passar um pouco da nossa visão que, muitas das vezes, é diferenciada dos outros profissionais de saúde (GF03).

O quadro de funcionários reduzido, associado, algumas vezes, com mão de obra auxiliar pouco qualificada, agrava a sobrecarga de trabalho, dificultando a implementação das açôes e melhorias esperadas pela acreditação para a assistência farmacêutica. 


\begin{abstract}
Os objetivos têm que ser comuns, a acreditação não pode estar em todos os setores, se seu administrador não te dar aumento de quadro. Então, essa dicotomia habita a minha cabeça, bastante e todo dia. [...]Eu acho que todos aqui que passaram pela acreditação, não conseguiram sem trabalhar em casa, final de semana. $\mathrm{O}$ horário de trabalho não é viável (GF01).

[...] E, querendo ou náo, o primeiro ponto que você pensa é: tem mais trabalho, isso aqui não vai dar pra implantar, isso aqui nunca vai funcionar, isso aqui também não vai pra frente; você sempre tende a pensar com pessimismo... (GF05).
\end{abstract}

Apesar de todo o esforço e envolvimento dos integrantes para obtenção do selo de certificação, não há incremento salarial para o grupo da farmácia hospitalar, resultando em uma demasiada frustração da equipe de farmacêuticos e, consequentemente, alta rotatividade de colegas de trabalho.

Você tem que cumprir 400 protocolos em um hospital, sem ganhar nada? Então, ele vai pra qualquer lugar que não tenha isso. [...]Quantos farmacêuticos você acha que eu tive em um ano? Alta rotatividade (risos). Não ficava nem 15 dias (GF02).

\title{
Discussão
}

São escassos na literatura estudos que abordem a temática da acreditação e sua relação com a assistência farmacêutica, sendo essa a principal contribuição deste trabalho.

Apesar de a acreditação ser vista por muitos profissionais como um processo puramente mercadológico (BRITO etal., 2017), os encontros permitiram uma discussão produtiva sobre o papel da farmácia hospitalar, pautada natransição gradativa das atividades executadas por esse setor hospitalar, cujo foco de atenção principal deixa de ser apenas o medicamento e passa a ser também o paciente. Esta mudança nos processos de trabalho a partir da acreditaçáo hospitalar foi também observada por Mendes e Mirandola (2015) e por Nomura e colaboradores (2016), esses últimos referindo-se especificamente à qualidade dos registros de enfermagem.

No entanto, apesar de essa mudança ser reconhecida pelos atores envolvidos no grupo, ainda está presente na percepção de muitos profissionais de saúde e gestores de unidades hospitalares a ideia de que a farmácia hospitalar é primariamente centrada na questão logística, envolvida principalmente no processo de provisão do medicamento (BARBOSA, 2015). De fato, seria utópico pensar que todos os serviços de uma farmácia hospitalar poderiam passar do enfoque meramente logístico 
para um modelo focado na clínica em curto espaço de tempo, já que as açôes do farmacêutico hospitalar, que visam melhorar os resultados da farmacoterapia, ainda são relativamente recentes no Brasil (ARAÚJO; FREITAS, 2006; PENAFORTE et al., 2007; SILVA et al., 2013). Por outro lado, o uso correto e eficaz dos medicamentos não pode estar dissociado da gestão desses produtos, uma vez que a integralidade das açóes e serviços de saúde ao paciente também esta relacionada às açôes e serviços de assistência farmacêutica, representados especialmente pelos processos de compra, armazenamento e distribuição de medicamentos. (CORADI, 2012).

Um estudo que avaliou a assistência farmacêutica em unidades de saúde de Ribeirão Preto, sob a perspectiva de farmacêuticos, constatou que a orientação das atividades da farmácia hospitalar ainda permanecia vinculada ao controle de estoque, ancorada na justificativa da garantia do acesso ao medicamento (ARAÚJO; FREITAS, 2006).Vale ressaltar que Oliveira e Matsuda (2016), ao estudarem a percepção dos profissionais sobre o motivo da desqualificação de um hospital da região sul do Brasil no processo de acreditação, observaram que a ocorrência de evento sentinela foi apontada como responsável pela decisão gerencial de deixar o processo de acreditação. Os autores enfatizam ainda o papel de indicadores de prevenção de eventos adversos no processo de acreditação. Isso reforça a importância de envolvimento da farmácia nos processos de cuidado e segurança do paciente.

A percepção de que a sobrecarga de trabalho, o alto nível de estresse são elementos que dificultam a atuação do profissional está de acordo com os achados de Cunha (2012), que também identificou que a sobrecarga de trabalho por falta de mais profissionais, o estresse demasiado pelo grau de responsabilidade e a excessiva interferência da atividade profissional na vida particular atuam como os fatores negativos advindos da atividade farmacêutica hospitalar.

A clareza dos gestores, quanto à existência de diferentes processos no âmbito da assistência farmacêutica, ainda é relativa. Tal fato representa um importante obstáculo na busca contínua pela qualidade da assistência farmacêutica e um verdadeiro paradoxo. A prática precisa ser entendida pelos gestores, não apenas como uma obrigatoriedade para a certificaçáo, mas sim como uma necessidade, que deve ser fomentada para o sucesso terapêutico. $O$ reconhecimento profissional uma justa remuneração e melhores condiçôes de trabalho são algunsdos fatores que podem colaborar como atrativos para o pleno exercício da assistência farmacêutica hospitalar. 
A percepção da necessidade de uma maior conscientização da administração hospitalar para melhorias naestruturação dosserviços defarmácia, profissionalização das equipes e uma atuação mais centrada no sucesso da terapia medicamentosa observada está de acordo com os resultados de Mendes e Mirandola (2015). Ao analisarem seis hospitais que passaram por acreditação no Estado de São Paulo, os autores observaram a necessidade de investimento na estrutura das unidades hospitalares.

Foi unânime a percepção de que é preciso melhorar a formação acadêmica do farmacêutico, garantindo postura gerencial e forte embasamento assistencial. A preocupação com a formação do profissional farmacêutico levou a ONA a oferecer, em 2017, um curso de Aperfeiçoamento em Farmácia Hospitalar e Clínica (ONA, 2017).

Silva (2003) aponta que o papel do farmacêutico está marcado por uma crise de identidade, decorrente de um agir administrativo e, muitas vezes, anônimo, cercado de pouco preparo técnico e quase nenhuma autonomia gerencial para promover mudanças. Araújo e Freitas (2006) reforçam estas premissas ao afirmarem que a gestão do uso de medicamentos e produtos para saúde tem como forte componente, além do conhecimento técnico, as relaçôes interpessoais e a habilidade de comunicação em linguagem adequada, o que pode ser um fator limitante para execução de procedimentos pelos profissionais atuantes na farmácia hospitalar.

Os resultados demonstram que a acreditação trouxeà tona a figura do farmacêutico, uma vez que os outros profissionais de saúde veem este profissional como mais um responsável pelo cuidado, no que concerne à farmacoterapia, criando uma divisão de tarefas e responsabilidades. No entanto, isto aumenta o nível de exigência de todos sobre a participação da farmácia no processo de cuidado, contribuindo para uma visão cada vez mais crítica sobre os processos da farmácia hospitalar. Este resultado está de acordo com os resultados de Mendes e Mirandola (2015), que apontam o crescimento do envolvimento profissional como um dos efeitos da acreditaçáo hospitalar.

No Brasil, a formação acadêmica ainda não oferece um preparo adequado para o completo exercício da assistência farmacêutica, dada a pouca atividade prática junto ao usuário do medicamento (ARAÚJO; FREITAS, 2006) e ao sistema de saúde. A readequação da grade curricular dos cursos de farmácia, oferecida pelas universidades brasileiras, poderá colaborar, no sentindo de tentar minimizar esta deficiência na medida em que considere um modelo de sistematização da prática assistencial, contemplando conhecimentos clínicos e holísticos, que possibilitarão 
uma atuação mais eficaz do farmacêutico junto ao paciente (CHARLIE et al., 2010). Esta mudança é bastante enfatizada pelas Diretrizes Curriculares Nacionais do curso de Graduação em Farmácia publicadas em 2017, que preconizam que a formação na área do cuidado seja fortalecida (BRASIL, 2017).

Ainda em relação ao confronto entre os aspectos positivos e negativos do processo de acreditação, na visão dos farmacêuticos, observa-se que a valorização e o conhecimento adquiridos por cada indivíduo superaram a pressãoe a cobrança. É unânime a percepção de que é preciso atender às expectativas dos clientes internos e externos, a partir da gradativa construção de um novo serviço, amparado pelos recursos e aparatos tecnológicos para aumento da segurança e eficiência dos processos desenvolvidos pela farmácia hospitalar. Esta visão de que mudanças na prática são necessárias para atender a processos de acreditação é apontada por Oliveira e Matsuda (2016), enfatizando ainda o papel do planejamento no alcance deste objetivo. No entanto, tanto para farmacêuticos quanto para os clientes internos da farmácia hospitalar, a qualidade do atendimento global oferecido ao paciente permanece aquém do desejado, uma vezque o ciclo da assistência farmacêutica ainda não se completa, gerando pouco efeito no receptor final, nesse caso, o paciente (BECHET et al., 2016; SMITH et al., 2017).

Também é preciso clarificar a compreensão dos diversos atores de que a construção de uma assistência farmacêutica de qualidade não está restrita apenas à dispensação e não pode ser atribuída unicamente à farmácia hospitalar, já que a responsabilidade pela cadeia de utilização de medicamentos é coletiva. $\mathrm{Na}$ prática, constatou-se que a responsabilidade pela assistência farmacêutica cabe, nas unidades do estudo, exclusivamente ao farmacêutico, pelo seu histórico de vínculo indissociável com o medicamento. Nesse sentido, há a desvalorização do trabalho coletivo, caracterizadopela visão de uma assistência farmacêutica multiprofissional. Assim, fica a dúvida de como garantir um trabalho clínico adequado, se as bases estruturais da farmácia hospitalar parecem não estar tão solidificadas nos hospitais investigados, apesar das mudanças evidenciadas.

\section{Considerações finais}

$\mathrm{O}$ estudo identificou que o processo de acreditação afetou positivamente na assistência farmacêutica de cinco hospitais privados, na medida em que promoveu 
a construção de um ciclo de melhorias na farmácia hospitalar. O grupo focal permitiu identificar as mudanças e compreensóes que o processo de acreditação, vivenciado por farmacêuticos e seus clientes,promoveu, resultando em modificaçôes significativas e no progresso na assistência farmacêutica hospitalar.

As falas demonstraram que, apesar dos avanços, os farmacêuticos reconhecem que a reorientação do serviço ainda não é suficiente, pois não foi percebida por alguns profissionais. Esse processo só passa a ser visto pela equipe quando é possível observar sua implantação na prática do cuidado oferecido ao paciente. É evidente que ainda há dificuldades para a efetiva implementação de alguns dos processos planejados durante a acreditação, o que pode mascarar o real efeito das açôes exercidas pela farmácia hospitalar. De modo geral, as mudanças decorrentes da acreditação não só contribuíram para uma maior inserção da farmácia hospitalar nas atividades de cuidado, como também vem exigindo dos farmacêuticos uma postura cada vez mais ágil, aberta a mudanças de curto prazo, e, ao mesmo tempo, gerencial.

O universo pequeno de unidades, principal limitação deste estudo, sugere cautela na extrapolação dos resultados. Da mesma forma, a falta de alguns participantes pode ter dificultado a captura de percepçóes divergentes. No entanto, ao promover a reflexão das equipes sobre as mudanças conceituais e comportamentais que emergem do processo de acreditação no âmbito da assistência farmacêutica, este estudo reafirma a importância da inserção da farmácia hospitalar no cuidado, como medida para a continuidade da assistência prestada ao paciente.

O caminho a ser percorrido ainda é longo, mas a mobilização em prol da qualidade da assistência farmacêutica, amparada pela acreditação, certamente promoverá profundas reestruturaçóes nesse segmento. Dessa forma, espera-se contribuir para uma visão mais ampla do papel da acreditação, imbuído na farmácia hospitalar e na melhoria da qualidade da assistência farmacêutica nos serviços hospitalares. ${ }^{1}$

\section{Referências}

ARAÚJO, A. L. A.; FREITAS, O. Concepçôes do profissional farmacêutico sobre a assistência farmacêutica na unidade básica de saúde: dificuldades e elementos para a mudança. Braz. J. Pharm. Sci. São Paulo, v.42, n.1, p. 137-146, 2006.

BARBOSA, K. S. S. Gerenciamento de Farmácia Hospitalar: otimização da qualidade, produtividade e recursos financeiros. Revista Saúde e Desenvolvimento, v.7, n.4, p. 6-25, 2015. 
BECHET, C. et al. Hospital pharmacists seen through the eyes of physicians: qualitative semistructured interviews. Int J Clin Pharm, v. 38, n. 6, p. 1483-1496, 2016.

BRASIL. Conselho Nacional de Educação. Câmara de Educação Superior. Resolução CNE/ CES 6, de 19 de outubro de 2017. Institui Diretrizes Curriculares Nacionais do Curso de Graduação em Farmácia. Disponível em:<http://portal.mec.gov.br/index.php?option=com docman\&view=download \&alias=74371-rces006-17-pdf\&category_slug=outubro-2017pdf\&Itemid=30192>.Acessoem:7 maio 2018.

- Ministério da Saúde. Diretrizes para estruturação de farmácias no âmbito do sistema Único de Saúde. Brasília: Ministério da Saúde, 2009. 44p.

BRITO, L. A. L.et al. Práticas de gestão em hospitais privados de médio porte em São Paulo, Brasil.Cad. Saúde Pública. Rio de Janeiro,v. 33,n.3, e00030715, 2017. Disponível em: <http:// www.scielo.br/scielo. Php?Script=sci_arttext\&pid=S0102-311X2017000305006\&lng=en\&nr $\mathrm{m}=\mathrm{ISO}>$. Acesso em: 25 ago.2017.

CAMPOS, C. J. G. Método de análise de conteúdo: ferramenta para a análise de dados qualitativos no campo da saúde. Rev Bras Enferm, v.57, n. 5, p. 611-4, 2004.

CHARLIE, B. S. I. et al. A holistic and integrated approach to implementing cognitive pharmaceutical services, Ars Pharmaceutica. Granada, v. 57, n. 2, p. 69-87, 2010.

CORADI, A. E. P. A importância do farmacêutico no ciclo da Assistência Farmacêutica. Arquivos Brasileiros de Ciências da Saúde, v. 37, n. 2, p. 62-4, 2012.

CUNHA, J. M. F. Dimensionamento da força de trabalho em uma farmácia hospitalar estadual: uma proposta de implantaçáo nas unidades hospitalares Estaduais de alta complexidade de Santa Catarina. 2012. 105 f. Monografia (Especialização) - Curso deGestão do Trabalho e Educação em Saúde, Florianópolis, 2012.

FELDMAN, L. B.; GATTO, M. A. F.; CUNHA, I. C. K. O. História da evolução da qualidade hospitalar: dos padróes a acreditação. Acta Paul. Enferm. São Paulo, v.18, n. 2, p. 213-219, 2005.

GONSALVES, Z. S. Modelo de Administração Estratégica em Farmácia Hospitalar: o caso do INTO. 2012. 135 f. Dissertação (Mestrado Profissional em Saúde Pública) - Escola Nacional de Saúde Pública Sérgio Arouca, Fundação Oswaldo Cruz, Rio de Janeiro, 2012.

MANZO, B. F. Implicaciones del proceso de acreditación para los pacientes desde la perspectiva de los profesionales de enfermería. Enfermería global. Murcia, v.25, n.1, p.262-71, 2012.

MENDES, G. H. S.; MIRANDOLA, T. B. S. Acreditação hospitalar como estratégia de melhoria: impactos em seis hospitais acreditados. Gest. Prod., v. 22, n.3, p. 636-648, 2015.

Messeder, A. M.; OsÓRIO-DE-CASTRO, C. G. S.; CAMACHO, L. A. B. Projeto Diagnóstico da Farmácia Hospitalar no Brasil: uma proposta de hierarquização dos serviços. Cad. Saúde Pública. Rio de Janeiro, v. 23, n.4, p.835-844, 2007. 
NOMURA, A. T. G.; SILBA, M. B.; ALMEIRA, M. A. Quality of nursing documentation before and after the Hospital Accreditation in a university hospital. Rev. Latino-Am. Enfermagem. Ribeirão Preto,v. 24,e2813,2016. Disponível em: <http://www.scielo.br/scielo.php?Script=sci_ arttext\&pid=S0104-11692016000100422\&lng=en\&nrm=ISO>. Acesso em:5 set.2017.

OLIVEIRA, J. L. C.; MATSUDA, L. M. Disqualification of certification by hospital accreditation: perceptions of professional staff. Texto contexto -Enferm.Florianópolis,v. 25, n. 1, p. 1-8, 2016.

ORGANIZAÇÃO NACIONAL DE ACREDITAÇÃO. ONA lança novo curso de Farmácia Hospitalar e Clínica. Disponível em:<https://www.ona.org.br/Noticia/425/ONA-lanca-novocurso-de-Farmacia-Hospitalar-e-Clinica>. Acessoem: 30 ago. 2017.

OSORIO-DE-CASTRO, C. G. S.; CASTILHO, S. R. (Org.). Diagnóstico da Farmácia Hospitalar no Brasil. Rio de Janeiro: ENSP/Fiocruz, 2004. 152p.

PENAFORTE, T.R.; FORSTER, A.C.; SIMÓES, M.J.S. Evaluation of the performance of pharmacists in terms of providing health assistance at a university hospital. Clinics. São Paulo, v.62, n.5, p.567-572, 2007.

RODRIGUES, E. A. A. Uma revisão da acreditação hospitalar como método de avaliação de qualidade e da experiência brasileira. 2004. 75 f. Dissertação (Mestrado Profissional) - Programa de Gestão de Sistemas e Serviços de Saúde, Escola Nacional de Saúde Pública Sérgio Arouca, Fundação Oswaldo Cruz, Rio de Janeiro, 2004.

SANTANA, R. S. et al. Assistência farmacêutica de uma rede de hospitais públicos: proposta de utilização das diretrizes ministeriais para avaliação do serviço. Revista Brasileira de Farmácia Hospitalar e Serviços de Saúde. São Paulo, v. 4, n. 1, p. 29-34, 2013.

SCHIESARI, L. M. C. Cenário da Acreditação Hospitalar no Brasil: evolução histórica e referências externas. 1999. 162 f. Dissertação (Mestrado) - Curso de Administração Hospitalar, Faculdade de Saúde Pública, Universidade de São Paulo, São Paulo, 1999.

SILVA, M. J. S. et al. Avaliação dos serviços de farmácia dos hospitais estaduais do Rio de Janeiro, Brasil.Ciênc. saúde coletiva, v. 18, n.12, p.3605-3620, 2013.

SILVA, R. R. Acreditação de farmácias: a construção de um modelo. 2003. 197 f. Tese (Doutorado em Saúde Pública) - Faculdade de Saúde Pública, Universidade de São Paulo, São Paulo, 2003. SMITH, M. G. et al. Pharmacy characteristics associated with the provision of medication management services within an integrated care management program. Journal of the American Pharmacists Association, v. 57, n.2, p. 217-221, 2017.

SOCIEDADE BRASILEIRA DE FARMÁCIA HOSPITALAR. Padróes minimos para a farmácia hospitalar e serviços de saúde. Goiânia: SBRAFH, 2007. 19p. 


\section{Nota}

${ }^{1}$ E. Bouças participou da concepção do estudo, coleta, análise e interpretação dos dados, redação do artigo e aprovação da versão final a ser publicada. T. R. Martins, D. O. Futuro e S. R. de Castilho colaboraram na concepção do estudo, redação e revisão crítica do artigo e aprovação da versão final a ser publicada. 


\section{Abstract}

Accreditation in the field of hospital pharmacy services: a qualitative approach of its effects

This study analyzes the impact of the accreditation process on hospital pharmacy services, aiming to identify evidence of changes and improvements in the service provided by the hospital pharmacy. Focus groups were conducted with pharmacists and internal clients of the pharmacy service of five private hospitals in the state of Rio de Janeiro intentionally selected. Recordings were made, later transcribed, to analyze the content of the dialogues and thematic categorization. According to the narratives, the accreditation resulted in investments both in infrastructure and human resources, implementation of new processes and discreet change in the performance of the pharmacist, leveraged by the clinical pharmacy. It was observed that such modifications contributed to a continuous transformation of hospital pharmacy services, with a modest improvement in the efficiency, quality and safety of the service provided. When considering the final results, the satisfaction was partial, since the pharmaceutical assistance cycle is not yet complete, weakening the processes recently implemented in favor of the quality of care offered to the patient. Despite of this aspect, the impact on the overall performance of the hospital pharmacy was considered positive, allowing to conclude that the accreditation guidelines pointed the way for the development of the evaluated services, as they required the fulfillment of the standards necessary for qualifiedpharmacy services.

Keywords: health assessment; accreditation; hospital pharmacy service. 